\title{
New way to dampen the energy of medium- and high-pressure flows
}

\author{
Alim Guryev, Nartmir Khanov, Olga Mareeva, Vasilii Fartukov, Anna Zhuravleva, and \\ Aleksandra Verkhoglyadova* \\ Russian State Agrarian University-Moscow Timiryazev Agricultural Academy, Moscow, Russia
}

\begin{abstract}
The current practice of hydraulic engineering construction applies four methods for damping extra energy of excess water discharge: throwing out the stream into the tailwater; using twisting of the stream in the water passageway, in a water-well, and on a multistage drop; and energy damping in a vertical shaft. The cheapest method is energy damping by throwing the jet into the downstream reservoir. The main disadvantages limiting the use of this method include the need for appropriate topographic conditions in the tailrace basin, strong rocks in the river channel, and the possibility of water throwing at a large distance from the hydropower project, which restricts the use of this method. Extra energy damping with the use of twisting flow in the water passageway requires complex structures, providing for a rotational movement of water and forming a deep vacuum in the outlet conduit. The breaking of vacuum requires a large amount of air, which causes dynamic modes, and its removal complicates the design of energy damping structures. The most reliable way of energy damping is damping in a stilling well. But the disadvantages of water-sucking wells are low efficiency accompanied by an uneven distribution of specific discharges in the inlet section and a sharp increase in the cost at high-pressure hydroelectric installations. The use of multistage cross-fall drastically facilitates the operation of a stilling well and serves as its supplement. Energy damping in a vertical shaft is easy to use. Still, it results in trapping a large amount of air at all operating modes, which has limited its practical use in hydraulic engineering construction. However, the damping of flow energy in a vertical shaft except for possible air supply has shown high efficiency of operation in combination with a diversion water pipe with a reverse slope. A variant of such design of flow energy damping in a vacuum vertical shaft has been developed and studied as applied to conditions of the Rogun hydropower project. Model studies of the design on the scale of 1:100 showed high efficiency and reliability in all possible ranges of discharged flow rates.
\end{abstract}

\section{Introduction}

Currently, four basic systems are most commonly used for damping the energy of the discharge flow of high-pressure hydropower projects (HPPs):

\footnotetext{
*Corresponding author: asverhogladova@yandex.ru
} 
1. Damping excess energy by throwing out the stream into the tailwater in the plunge basin. Examples of the application of this method of damping energy include the spillways of the Bratsk, Krasnoyarsk, Ust-Ilimsk HPPs, etc. [1].

2. Damping excess energy by twisting of the stream in the water passageway. Examples of this method include the spillway of the Teri HPP and some variants of the spillways of the Rogun HPP [2].

3. Damping excessive energy in a water-well, which is the end structure of the spillway. Examples of this method include the spillways of the Sayano-Shushenskaya, Zeya, Vilyuy HPPs, etc. [3].

4. On the spillway surface of the dam, which, in essence, is a multistage drop, as exemplified by spillway No.2 of the Boguchany HPP (the HPP of China), and is, in fact, an additional element of a stilling water-well as in spillway No.2 of the Boguchany HPP, or a system of stilling water-wells, that used in the Sayano-Shushenskaya HPP $[4]$.

5. Energy damping in a vertical shaft, where additional power is generated to reduce the hydrodynamic pressure of the flow to the bottom of the shaft while damping the energy of low water flows [5].

In several cases, for example, at the Rogun HPP, none of the known methods ensure rational application due to the winding channel and insufficient strength of the rocks it is made of. These conditions immediately make inapplicable energy damping by throwing the water jet into the tailwater. The use of energy-damping structures with swirling of the flow due to increased heads (more than 300 meters) requires lining energy damping chambers with thick-walled steel sheets and overcome great difficulties in combating cavitation and removing air in the end devices. At present, energy is damped in stilling water well, which, due to the high energy and flow rate, required high costs for its construction and even more for rock work required for the construction of this well. Rather high steepness of slope cutting lowers its stability and may cause landslides, especially given the seismicity of the construction area. The issue of damping energy in a vertical open shaft under these conditions was not even considered [10-15].

Under these conditions of construction of the Rogun HPP, it was necessary to develop a fundamentally new technical solution to eliminate or at least mitigate the disadvantages of the existing methods of damping the energy of the discharged flow.

\section{Methods}

\subsection{Requirements for a flow energy damping device for high-pressure hydropower projects}

Analysis of the negative consequences associated with each of the energy damping methods makes it possible to formulate the requirements for the flow energy damping device as applied to the conditions of the Rogun HPP. This may help eliminate these shortcomings.

1. Damping the flow energy outside the spillway structure.

It is necessary to damp the energy before the flow enters the tailwater.

2. Eliminating the appearance of transient modes in the outlet tunnel when a variable value of the discharge flow rate is formed.

It is necessary to apply a design of the outlet tunnel, which would prevent the formation of various-shape curves of the free surface of the flow in the outlet tunnel when the flow rate changes. This condition is most satisfied by a tunnel with a reverse slope, in which a free surface takes the form of a drop-down curve, which ensures the tunnel sealing from its 
inlet to outlet section during the transition from the pressure to non-pressure mode and vice versa.

3. The presence of a burst air discharge from the tunnel.

The formation of this mode is associated with the use of tunnels with a straight slope. When water movement enters the pressure mode, a "conflict of interests" of air and water arises: the air in the arch apex zone tends to move up the slope, while the water flows down the slope. As a result, an air pocket appears under the tunnel roof, which tends to move against the current. As the air pocket size increases, its drag grows, and when the value of the lifting force is reached, it is carried out by the stream into the tailwater. The air pocket release into the atmosphere is accompanied by a hydraulic hammer shock in the tunnel, not to mention noise effects

A negative slope of the outlet tunnel removes this "conflict of interest" and provides for a smooth flow of water in the tunnel under all hydraulic modes of its operation.

4. A reverse slope of the outlet tunnel ensures stable operation in the entire range of possible discharge rates. If there is no flow due to previous water discharges, the tunnel will be partially filled up to the bottom of the outlet section. This volume of water will have a horizontal surface with a maximum depth equal to the value $h_{\max }=i \cdot l$ at the beginning of the tunnel, where $i$ - the slope of the tunnel bottom, and $l$-its length.

When the tunnel is switched on, a drop-down curve will be formed in it, a characteristic feature of a critical depth and a maximum depth at the beginning of the tunnel in the exit section. In this case, one should consider the hydraulic characteristics of water conduits with a circular cross-section: their maximum capacity $Q_{\max }$ is provided at an impounding $h / d=0.942$. Figure 1 shows the relationship between the flow rate through the circular water conduit in fractions of the maximum and the relative impounding $h / d$. As can be seen from the graph, when operating with the entire cross-section, the water conduit passes only $0.93 \mathrm{Q}_{\max }$ of the maximum flow. At the same time, this flow rate, corresponding to the filled tunnel, will be observed at an impounding $h / d=0.82$.

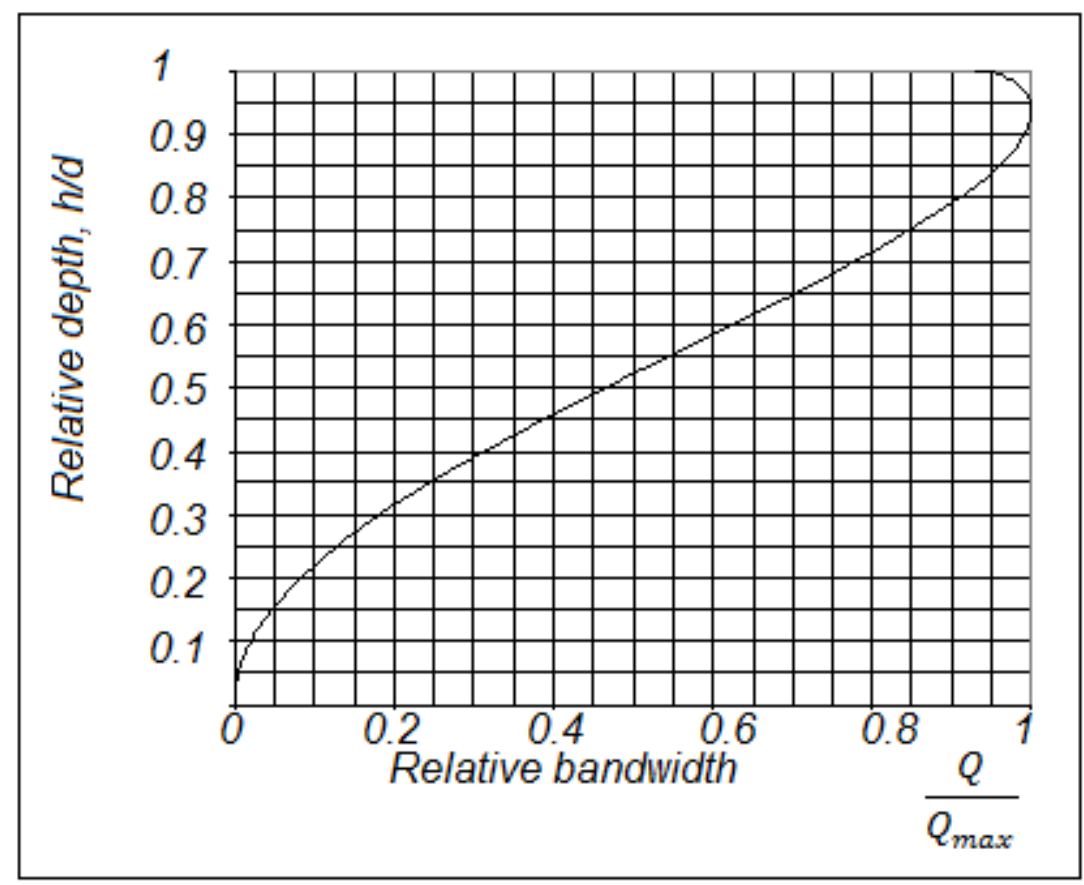

Fig. 1. Relationship between the relative flow rate of circular water conduit and its impounding $h / d$ 
Consequently, forming a free surface in a tunnel with a circular cross-section will depend on whether there is an increase or decrease in flow rates in the tunnel. As flow rates increase, the change in the maximum depth of water in the tunnel will occur along the lower part of the curve in the graph (Fig.1).

Upon reaching an impounding $h / d=0.942$, the depth will jump abruptly to full filling, and the throughput will decrease by $7 \%$, respectively. To maintain the same capacity, a corresponding adjustment in the gate opening will be required; otherwise the reservoir level will rise.

As the tunnel flow rate decreases to become lower than $0.93 Q_{\max }$, the flow will be separated from the arch apex with a decrease in depth to the $h / d$ value $=0.82$, which must be considered in hydraulic analysis and the tunnel operation.

Figure 2 shows a graph of changes in the critical depths in a tunnel with a circular crosssection with diameters $d=14.0 \mathrm{~m}$, depending on the flow rate. As can be seen from this graph, at her $=0.942 d$, the section of the water conduit is abruptly recaptured, and when the flow rate drops by less than $0.93 \times 2200=2046 \mathrm{~m} 3 / \mathrm{s}$, the depth abruptly decreases to 13.0 $\mathrm{m}$.

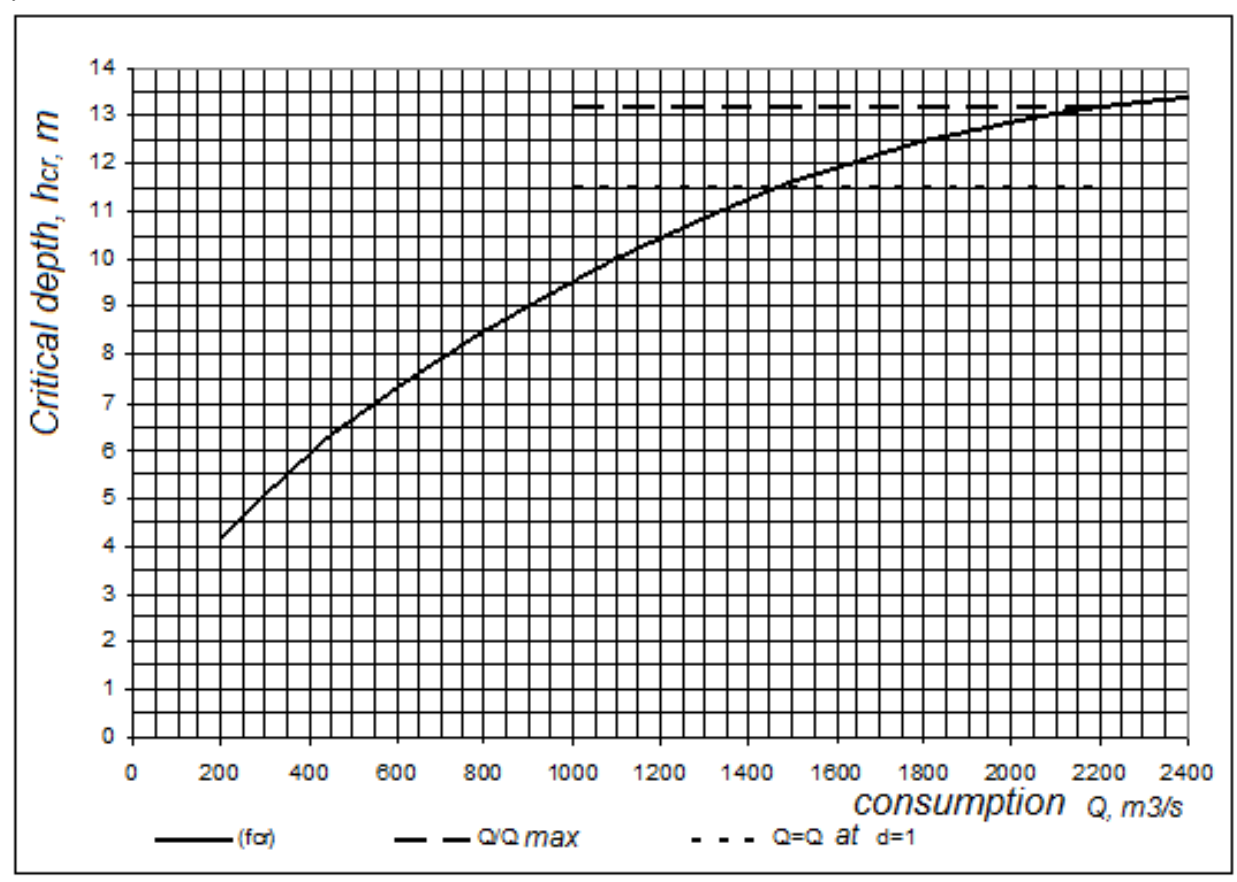

Fig. 2. Graph of changes in critical depths in a tunnel with a diameter (d) of $14.0 \mathrm{~m}$

\subsection{Fundamental technical solutions to meet the requirements for a device for damping the flow energy of high-head hydropower development}

Figure 3 shows a schematic longitudinal cross-section of a high-pressure spillway, making it possible to implement the above requirements for the flow energy damping device according to [6].

The structural features of the proposed design are as follows.

1. Energy of the passed flows is damped in a vertical shaft located behind the chamber of bulkhead gates. 
2. Flow rates are regulated by horizontal gates located above the ceiling of the flow energy damping shaft. Placing the shutters horizontally provides for simultaneous reduction of the shutter chamber height.

3. The outlet tunnel is located in the lower part of the flow energy damping shaft, directly above its bottom. If necessary, the shaft can be extended below the inlet section of the outlet tunnel.

4. The outlet tunnel is designed with a reverse slope.

5. For a more successful air release from the exhaust tunnel, an air duct may be placed above its apex, which can be made either in the form of an independent perforated air duct above the tunnel apex or in the form of a longitudinal slot in the tunnel apex.

6. A flow energy damping device in the form of a circular-cylindrical shaft allows routing the outlet tunnels in any direction.

To implement this design, the parameters of the control gates, the flow energy damping shafts, and the outlet conduit were determined.

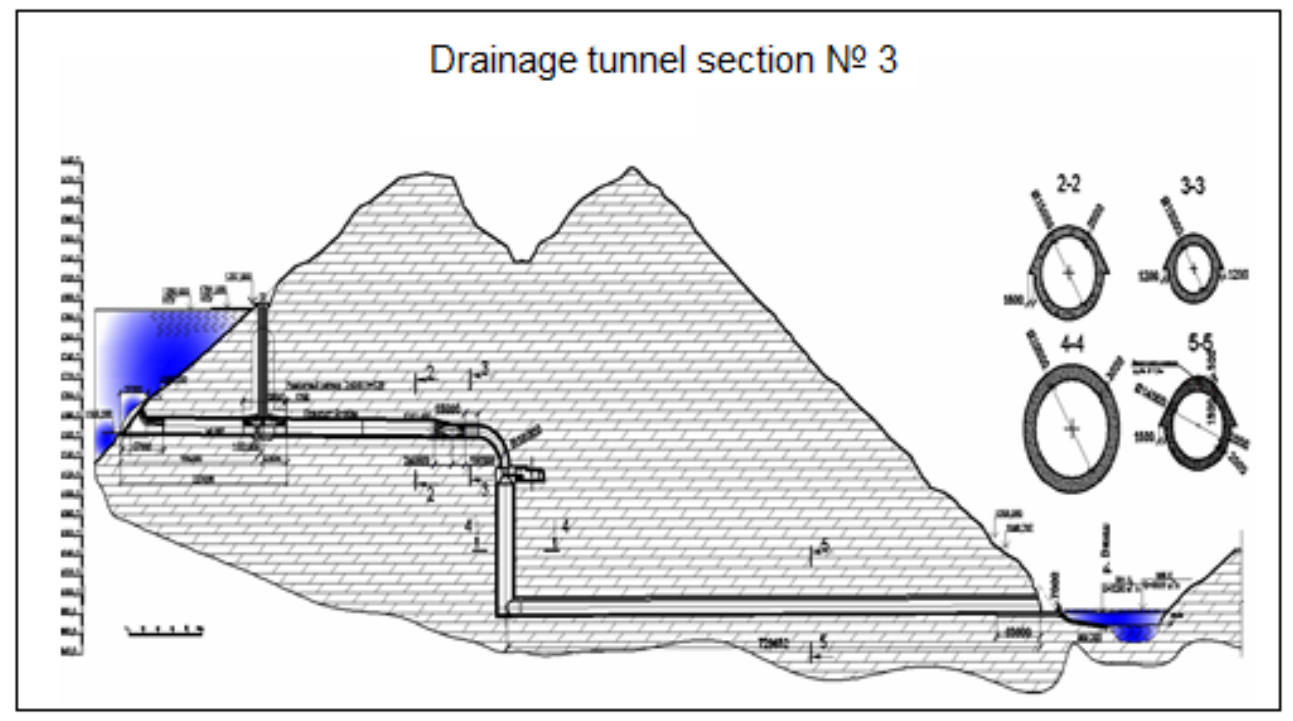

Fig. 3. Schematic longitudinal cross-section of a high-pressure spillway

In this variant, the calculated flow rate is $\mathrm{Q}=1800 \mathrm{~m}^{3} / \mathrm{s}$, the diameter of the shaft is $D_{s h}=$ $20.0 \mathrm{~m}$, and the diameter of the outlet tunnel is $d_{t}=14.0 \mathrm{~m}$.

During its operation with a full cross-section, the tunnel diameter of $14.0 \mathrm{~m}$ provides the maximum speed in the tunnel $\operatorname{Vmax}=11.7 \mathrm{~m} / \mathrm{s}$, which at the exit from the tunnel corresponds to the Froude number

$$
\operatorname{Fr}=\frac{V^{2}}{\mathrm{gd}}=\frac{11.7^{2}}{9.81 \cdot 14}=0.997=1
$$

One of the main problems associated with the passage of waste flows from the Rogun HPP is the safe discharge of waste flows into the river bed at a large angle to the axis - up to $90^{\circ},{ }^{\circ}$. The low kinetics of the flow in the outlet section of the proposed design ensures its controllability and satisfactory conflux with the river flow.

As a preliminary variant, the following design of the end device can be proposed. Following the studies of flow spreading [7-10], the central angle $\beta$ of a flow spreading on the horizontal plane can be determined from the relationship: 


$$
\operatorname{tg} \beta=\frac{1}{\sqrt{\mathrm{Fr}}}=\frac{1}{\sqrt{1}}=1
$$

This means that free flow spreading with an average spreading angle to the side $\beta / 2=22.5^{\circ}$ is provided. With the length of the spreading area, for example, of $20.0 \mathrm{~m}$, the width of the stream $B$ will be $B=14+2 * 20 * \operatorname{tg} 22.5^{\circ}=\mathrm{m}$. In this case, the specific flow rate will equal $q=1800: 30.6=58.9 \mathrm{~m}^{2} / \mathrm{c}$.

To reduce the magnitude of the specific flow rates flowing into the canal, it is possible to use the construction road along the canal as a trench outlet by arranging a distribution wall of variable width along the canal. With a length of this wall of $100 \mathrm{~m}$, the mine flow rate $Q=1800 \mathrm{~m}^{3} / \mathrm{c}$ can be injected into the canal with a maximum specific flow rate of only $q=18 \mathrm{~m}^{2} / \mathrm{c}$. Applying these initial data, we carried out model hydraulic studies of the spillway with a design head $H=300.0 \mathrm{~m}$ at a scale of $1: 100$.

\subsection{Model installation}

A schematic diagram of the model installation is shown in Figure 4.

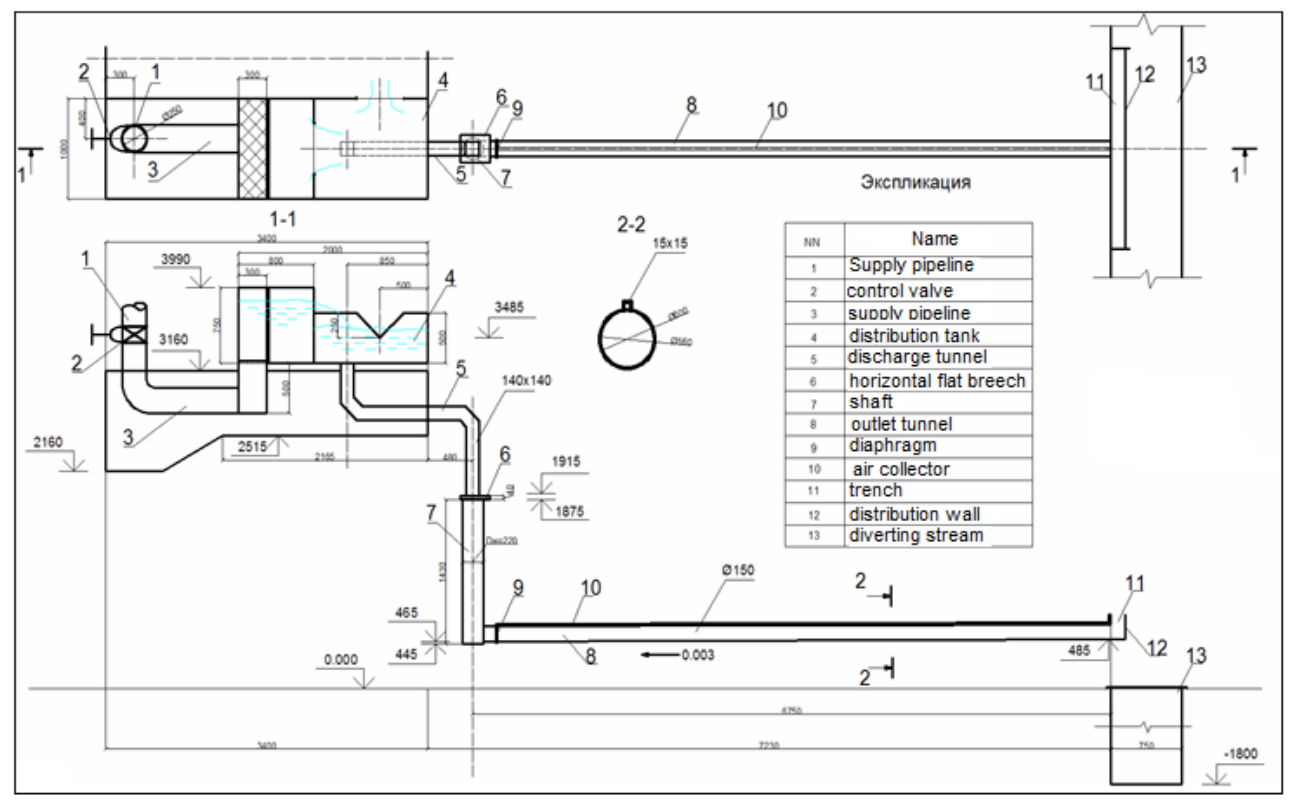

Fig. 4. Schematic diagram of a model installation of a high-pressure spillway

Figure 5 shows a photo of the general view of the model installation.

Figure 6 shows a photo of a pressure tank and energy damping shaft with a shutter chamber in the upper part and the initial section of the outlet tunnel of the model installation. 


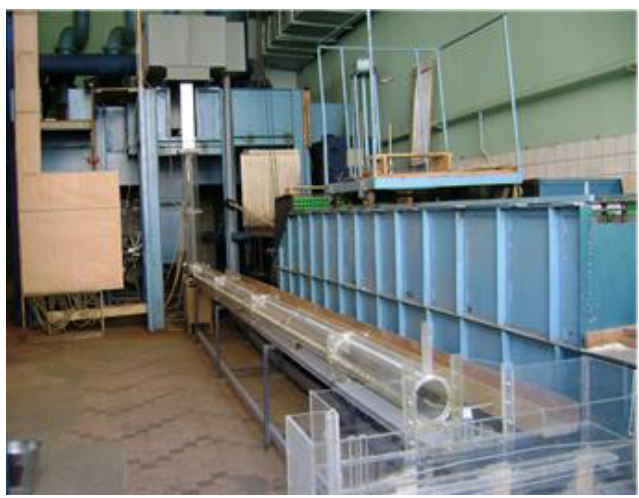

Fig.5. General view of the model high-pressure spillway installation

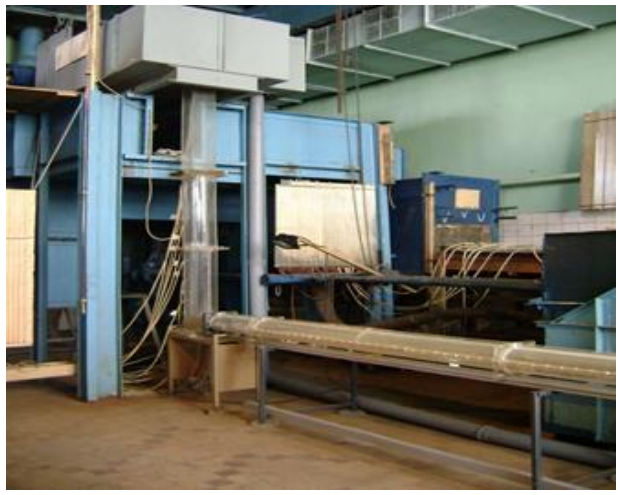

Fig. 6. The head section and the outlet tunnel of the high-pressure spillway model

Figure 7 shows a photo of the connecting structure between the tunnel and the canal, which is shown schematically on the model.

A schematic diagram of the design of a shutter chamber with horizontal gates is shown in Figure 8.

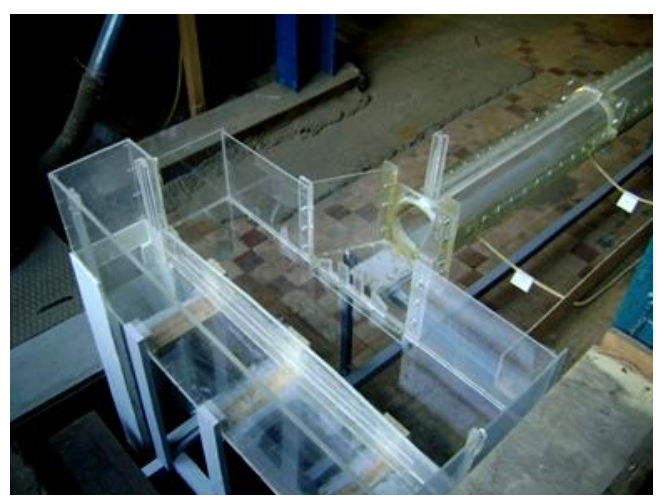

Fig. 7. Model of the end device with preliminary flow spreading and a slotted wall.

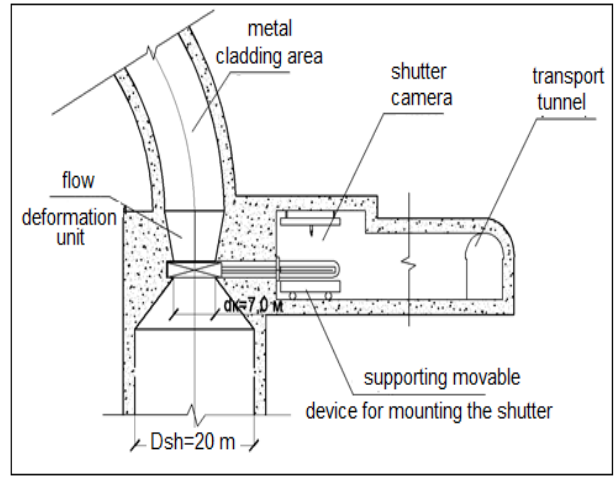

Fig. 8. Schematic diagram of the design of the shutter chamber with horizontal valves

For further research, a design of a shutter chamber with two gates was developed, the model of which is shown in Figure 9.

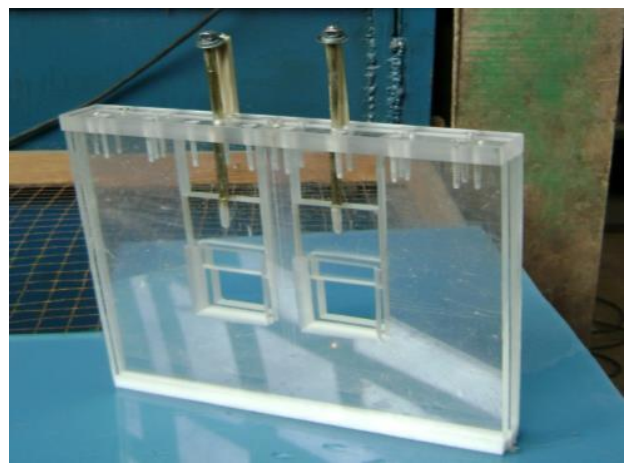

Fig. 9. Design of the shutter chamber with two shutters with a sharp edge 


\section{Results and Discussion}

\subsection{The results of studying the performance of vacuum shaft energy absorber}

Considering the novelty of the proposed design and the complete lack of information about the operation of water supply facilities in an absolute vacuum, research was carried out for two options for the operation of a shaft vacuum energy damper

At the first stage, the operation of the shaft damper with unlimited air supply to the energy damping shaft was studied to obtain reference parameters for subsequent evaluation to further evaluate the operation of the shaft damper in the vacuum mode. For this purpose, a hole with a diameter of $25 \mathrm{~mm}$ was made under the lock chamber on the outer surface of the shaft.

At the second stage, the operation of the shaft damper was studied with a complete cessation of air supply to the energy damping shaft. For this, an air flow meter was installed in the air supply hole, which was completely blocked at this research stage.

To assess the performance of the vacuum shaft for damping the flow energy, the following studies were carried out:

- the range of costs implying the use of this design;

- efficiency of flow energy damping;

- efficiency of air removal from the outlet tunnel with a negative slope;

- pressure distribution along the tunnel length;

- the efficiency of the flow spreading at the end conjugation structure

The discharged water flow rates in the entire possible range were regulated by two horizontally located rectangular gates with a cross-section of $b \times h=4.0 \times 5.0 \mathrm{~m}$. As the studies have shown, this gate chamber provided a flow rate of up to $3500 \mathrm{~m}^{3} / \mathrm{s}$, i.e., 2 times more than the calculated water consumption.

To assess the pressure distribution inside the vacuum shaft and the discharge tunnel, the entire culvert, starting from the chamber with a shutter to the end section of the discharge tunnel, was equipped with piezometers. The piezometric shield and the connection of piezometric tubes with piezometers are shown in Figures 5 and 6.

At low water flow rates, a shallow water depth was provided in front of the inlet section into the outlet tunnel to ensure large dynamic loads on the bottom of the energy damping shaft. To reduce this hydrodynamic pressure, the water level was artificially raised in front of the inlet section. For this purpose, a transverse diaphragm with a hole of $10 \mathrm{~m}$ in diameter $\left(d_{\text {hole }}=0.714 d_{\text {tun }}\right)$ was installed behind the inlet section of the outlet tunnel at a distance of $l=d_{t u n}=14 \mathrm{~m}$.

\subsection{The results of studying the operation of a shaft damper with unlimited air supply to the energy damping shaft}

The hydraulic modes in the energy damping shaft were studied visually due to a hydraulic model made of transparent plexiglass.

Figure 11 shows a photo of the lower section of the shaft and the initial section of the outlet tunnel $Q=180 \mathrm{~m}^{3} / \mathrm{s}$ with the opening of the gates $a / a_{o}=0,1$.

As shown in Figure 11, a water-air mixture is formed in the shaft and enters the outlet tunnel.

When water leaves the gate chamber, the water swiftly goes over for about 130 meters. It forms an expanding stream that reaches the walls at a water speed of up to $60 \ldots 65 \mathrm{~m} / \mathrm{s}$, which can be dangerous for concrete in terms of its physical destruction, and therefore air entrapment in the tunnel turns out to be small. The air quickly leaves the water at the beginning of the tunnel. 
As the opening of the gates increased to $a / a_{0}=0,4$, the discharge flow increased to $Q=870 \mathrm{~m}^{3} / \mathrm{s}$. The hydraulic picture at the lower section of the shaft and the initial section of the discharge tunnel is shown in Figure 12.

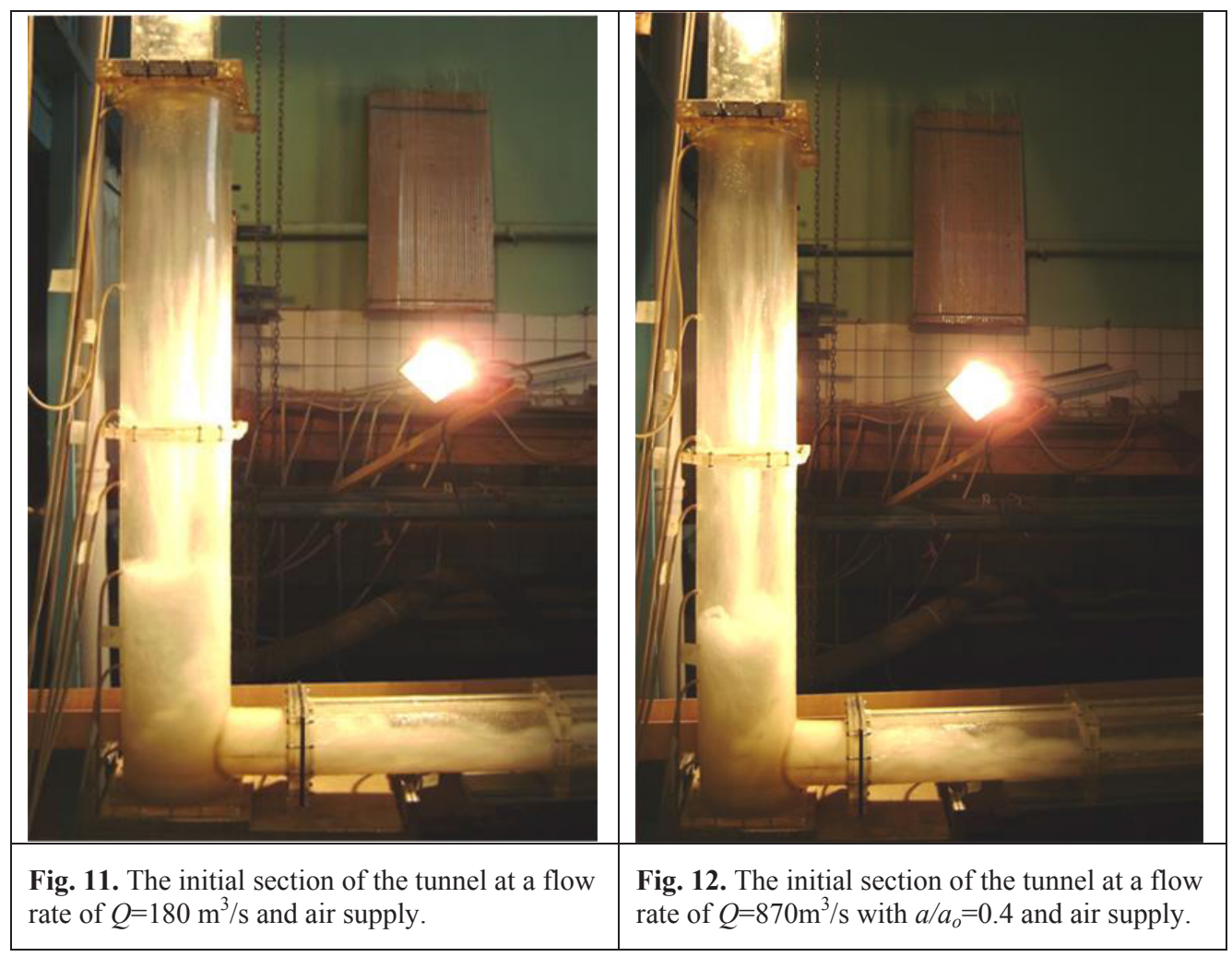

As shown in Figure 12, at an increase in the flow rate to $Q=870 \mathrm{~m}^{3} / \mathrm{s}$ the water depth in the tunnel increases to the $3 / 4$ value of the shaft height, which is about $137 \mathrm{~m}$. In this case, the water in the shaft becomes a water-air emulsion, which flows into the outlet tunnel. Behind the diaphragm, this water-air emulsion forms a jet that does not completely fill the crosssection of the outlet tunnel. Instead, intensive air separation occurs in a section about 2 diameters in length to form a practically free flow of air inclusions.

At the outlet section, a flow is formed with a rather steep drop-down curve, so a critical depth is formed in the outlet section, slightly less than half the tunnel diameter, as can be seen from Figure 13. 


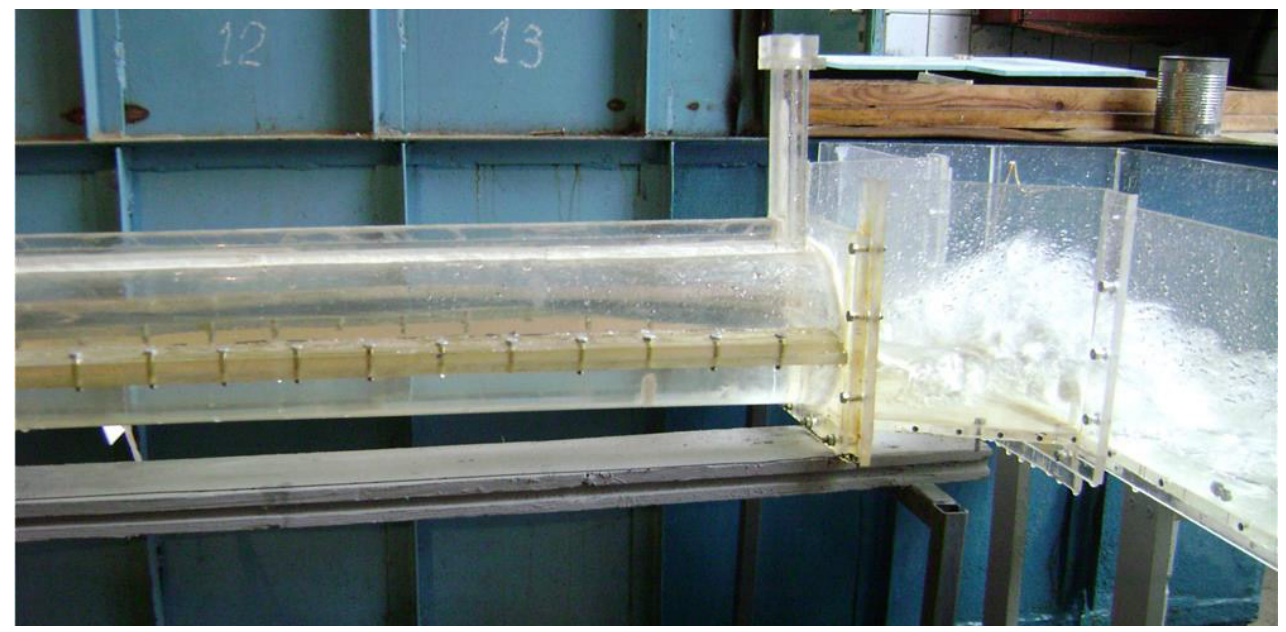

Fig. 13. Outlet section of the outlet tunnel at a flow rate $Q=870 \mathrm{~m}^{3} / \mathrm{s}$ with $a / a_{o}=0.4$ and air supply

An increase in the opening of the gates to $a / a_{o}=0,6$, leads to a discharge flow increase $Q=1360 \mathrm{~m}^{3} / \mathrm{s}$. The hydraulic picture at the lower section of the shaft and the initial section of the outlet tunnel is shown in Figure 14. In this case, the water in the shaft is actually a water-air emulsion, which enters the outlet tunnel. Behind the diaphragm, the water-air emulsion forms a jet that does not completely fill the cross-section of the outlet tunnel. However, in a section of about 2 diameters, there is intensive air separation, and then a stream is formed that is practically free of air inclusions. Along the entire length of the outlet tunnel, a free-flow mode of water movement is formed.

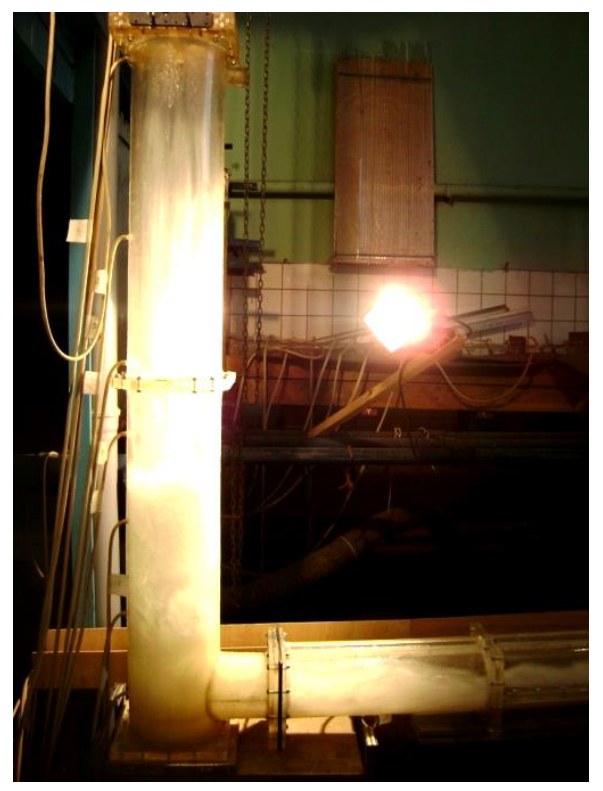

Fig. 14. Initial section of the tunnel at a flow rate $Q=1360 \mathrm{~m}^{3} / \mathrm{s}$ at $a / a_{o}=0,6$ and air supply.

At the outlet section, a flow is formed with a rather steep drop-down curve, where a critical depth is formed in the outlet section, about half the tunnel diameter, as can be seen from Figure 15. 


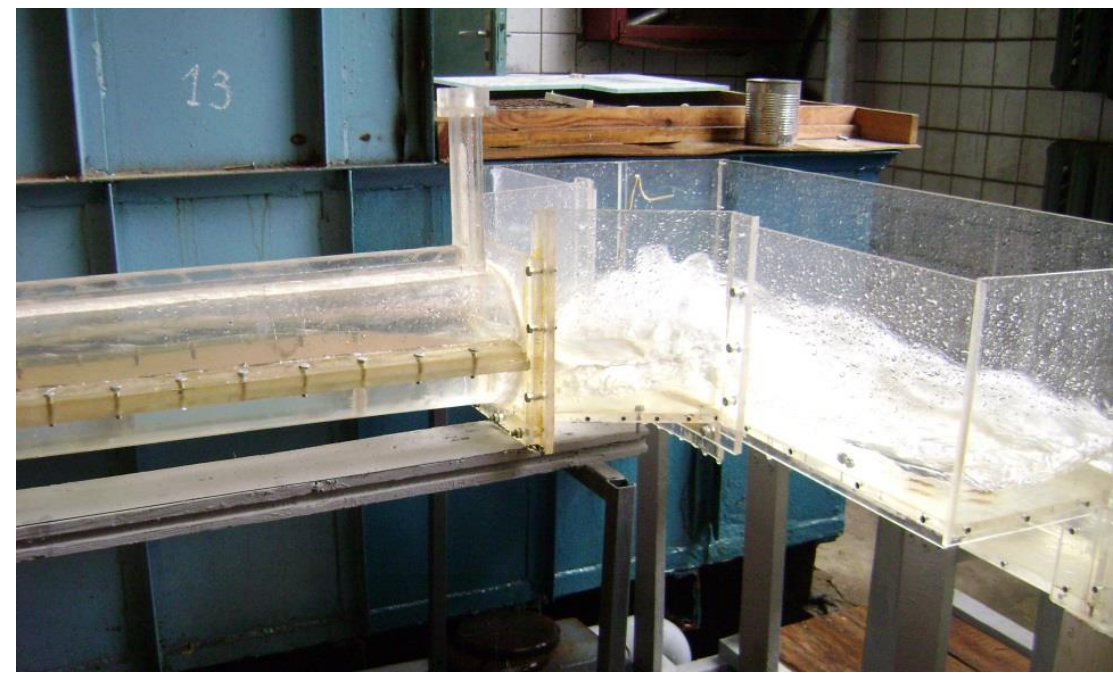

Fig. 15. Outlet section of the outlet tunnel at flow rate $Q=1360 \mathrm{~m}^{3} / \mathrm{c}$ with $a / a_{o}=0,6$ and the air supply/

When the gates are fully opened to $a / a_{o}=1.0$, the discharge flow increased to $Q=2300 \mathrm{~m}^{3} / \mathrm{s}$, which is $1.28 Q_{\text {calc }}$. The shaft contains a water-air emulsion, which enters the outlet tunnel. Behind the diaphragm, this water-air emulsion forms a jet that does not completely fill the cross-section of the outlet tunnel, but in a section of about 2 diameters in length, there is intensive air separation, and then a flow is formed that is practically free of air inclusions. Along the entire length of the outlet tunnel, a free-flow mode of water flow is formed.

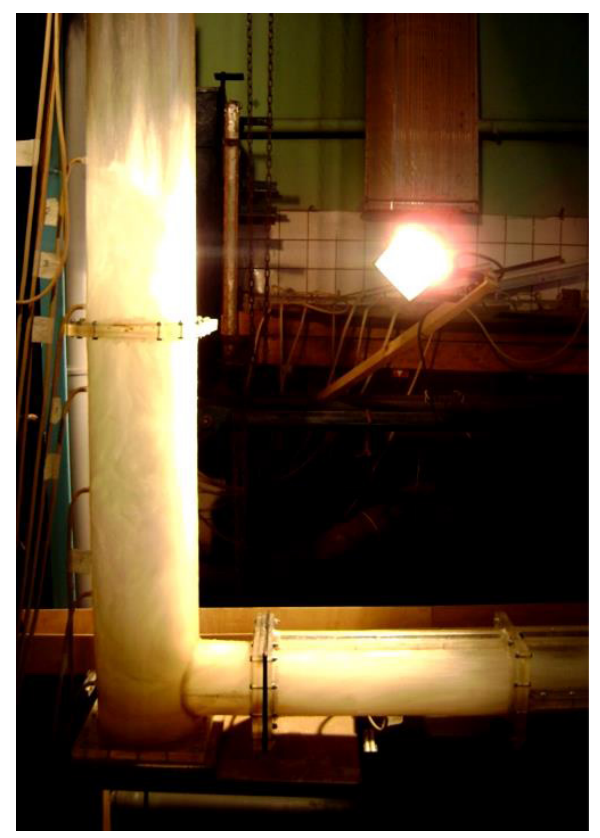

Fig. 16. Initial section of the tunnel at a flow rate $Q=2300 \mathrm{~m}^{3} / \mathrm{s}$ when $a / a_{o}=1.0$ and the air is supplied

At the outlet section, a flow is formed with a rather steep drop-down curve, when a critical depth is formed in the outlet section, slightly more than half the tunnel diameter, as can be seen from Figure 17. 


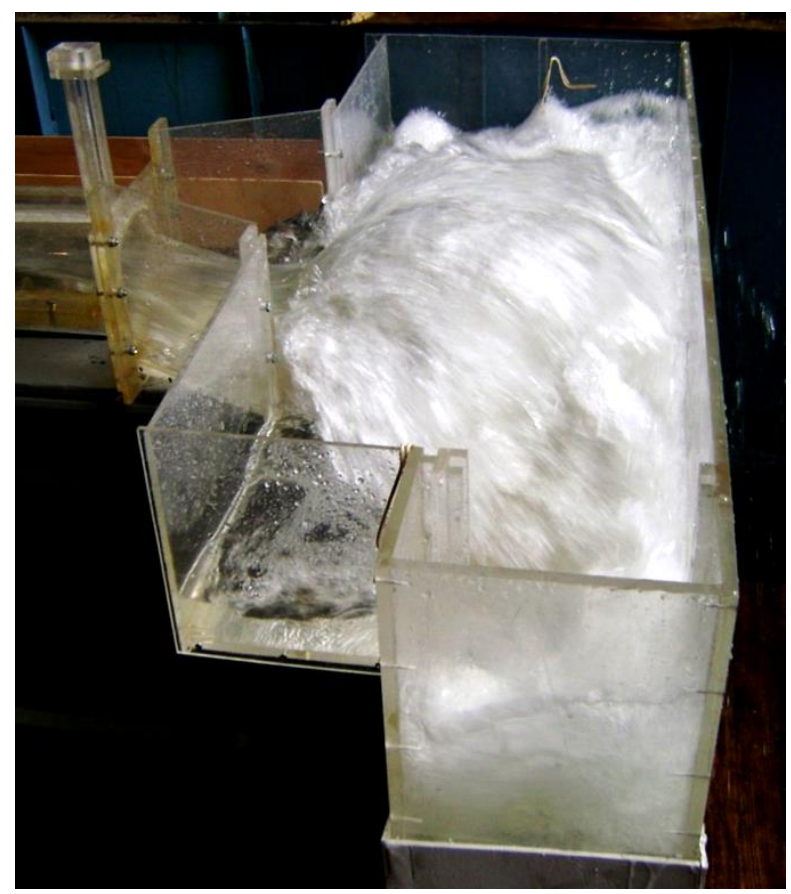

Fig. 17. Outlet section of the outlet tunnel at a flow rate $Q=2300 \mathrm{~m}^{3} / \mathrm{c}$ when $a / a_{o}=1.0$ and the air is supplied

Figure 17 also shows the operation of the accepted version of the conjugating structure. The initial parameters of the flow at the entrance to the conjugating structure are determined by its flow rate and the flow depth at the tunnel exit. Theoretically, from the standpoint of calculating the parameters of slowly changing motion, a critical depth $\mathrm{h}_{\mathrm{cr}}$ should be formed in the exit section of the tunnel. However, at the end sections of non-flooded structures, a drop-down curve with a large curvature is formed, leading to the development of significant inertia forces in the end section, which cause a deviation from the hydrostatic law of the pressure distribution along the flow depth. As a result, the depths in the outlet section of the structures become much lower than the critical value. According to research data $[8,9,10]$, the depth in the end sections and bends of linear structures is $(0,8 \ldots 0,65) \mathrm{h}_{\mathrm{cr}}$, so there is a turbulent flow with the corresponding hydraulic parameters in these sections. For this reason, a hydraulic jump wave is observed at the conjugating structure behind the first slotted wall, which is not always taken into account in the hydraulic analysis of hydroengineering structures.

\subsection{Operation of a shaft damper with a metered air supply into the energy damping shaft}

Stopping the air supply to the shaft for damping the flow energy leads to a sharp change in the hydraulic characteristics in the shaft. When the first portions of water enter the shaft after the gates are opened, air starts being intensively removed from the shaft to from depression in it. The air removal and vacuum formation in the shaft cause water to be sucked into it to a height equivalent to the discharge $\Delta \mathrm{z}=\mathrm{h}_{\mathrm{vac}} / \gamma_{\mathrm{w}}$, and on the other hand, leads to the intensified release of air dissolved in water. The vacuum value is determined by the relationship: 


$$
h_{\mathrm{vac}}=10,33-\frac{\nabla}{900}-p_{\text {bar }} \text { m.w.c. }
$$

Where; $\nabla$ is an absolute elevation of the terrain in the Baltic system of high-altitude coordinates;

$p_{\text {bar }} \approx 0.39 \mathrm{~m}$ is a change in baric pressure associated with the movement of cyclones. For mountainous terrain conditions with absolute marks of $500 \ldots 1000$ meters above the sea level, the vacuum can reach the value $h_{v a c}=9.38 \ldots 8.83$ m.w.c This value characterizes the difference in the depth of water in the shaft (a greater one) than the depth $\mathrm{H}$ required for the flow to pass. When the entire air volume in the shaft is removed, the vacuum is formed from there the incoming volume of water. According to the Dalton-Henry law, the relationship between the gas content in water and its temperature is determined by the graphs shown in Figure 18 (for atmospheric pressure $p_{a}=10.33$ m.w.c. and pressure $p_{a}=9.0$ m.w.c.

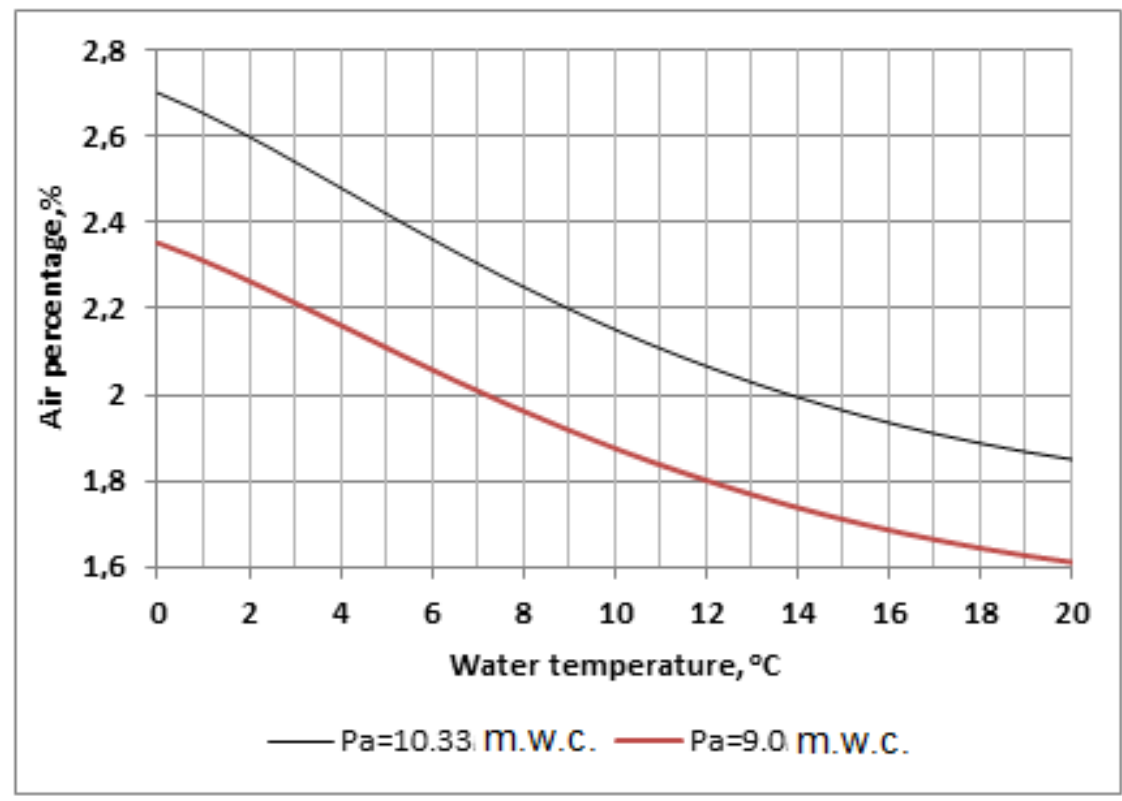

Fig. 18. Content of dissolved air in water

It can be assumed that the water temperature in the depths of the reservoirs will be within $6 \ldots 8^{\circ} \mathrm{C}$. At this temperature, the water contains about $2 \%$ of air by volume, which will be released from the water as the pressure in the shaft decreases due to the air removal from it by water. In the absence of air ducts supplying air to the shaft, absolute vacuum can be formed there. With a design flow rate $Q=1800 \mathrm{~m}^{3} / \mathrm{s}$, the flow rate of the released air can be $Q_{\text {air }}=0,02 \cdot 1800=36 \mathrm{~m}^{3} / \mathrm{s}$.

This air will be partly carried away by the flow and partly accumulate over the free surface, reducing the amount of vacuum. The released air volume expansion and pressure decrease will occur following the Boyle-Mariotte laws. To describe these processes in each specific case, it is necessary to perform the appropriate analyses.

When modeling hydraulic processes with vacuum, the modeling laws are violated. When water enters the shaft for quenching the flow energy on the model, the air will be removed until complete removal, as it happens naturally. But, as shown above, when an absolute vacuum occurs in the example under consideration at a shaft height of $150 \mathrm{~m}$ 
under the influence of a vacuum, the level can easily rise by $8 \ldots 9$ meters, leaving 140 meters of airless space above the water surface, then on a model where the shaft height is only 1.5 meters, only $1 / 6$ of the absolute vacuum value is enough to fill the shaft with water. This is exactly what happened while studying the shaft operation when the air supply from outside was stopped. Therefore, to simulate the similarity of water release on the model when establishing the flow rate of the spillway, using the graphs in Figure 18, the theoretically possible volume of air soluble in water at the temperature of laboratory water was calculated. Then the potential air flow rate was calculated, after which the shaft was supplied with a missing air flow up to $2 \%$. The air supply opening was equipped with a shut-off device with a gas flow meter to supply a metered air flow rate into the shaft.

For a visual assessment of the hydraulic processes of water movement in the zone of its intake from the shaft into the outlet tunnel and deformation of the falling flow in the water intake zone, the energy damping shaft was equipped with a stilling water-well in the form of a shaft extension of $70 \mathrm{~m}$ below the inlet section of the outlet tunnel.

Figure 19 shows water flow in the abutting zone of the outlet tunnel to the shaft at a spillway flow rate $Q=180 \mathrm{~m}^{3} / \mathrm{s}$ and air supply $Q_{a}=4 \mathrm{~m}^{3} / \mathrm{s}$.

Figure 20 shows water flow in the abutting zone of the outlet tunnel to the shaft at a spillway flow rate $Q=630 \mathrm{~m}^{3} / \mathrm{s}$ and air supply $Q_{a}=11 \mathrm{~m}^{3} / \mathrm{s}$.

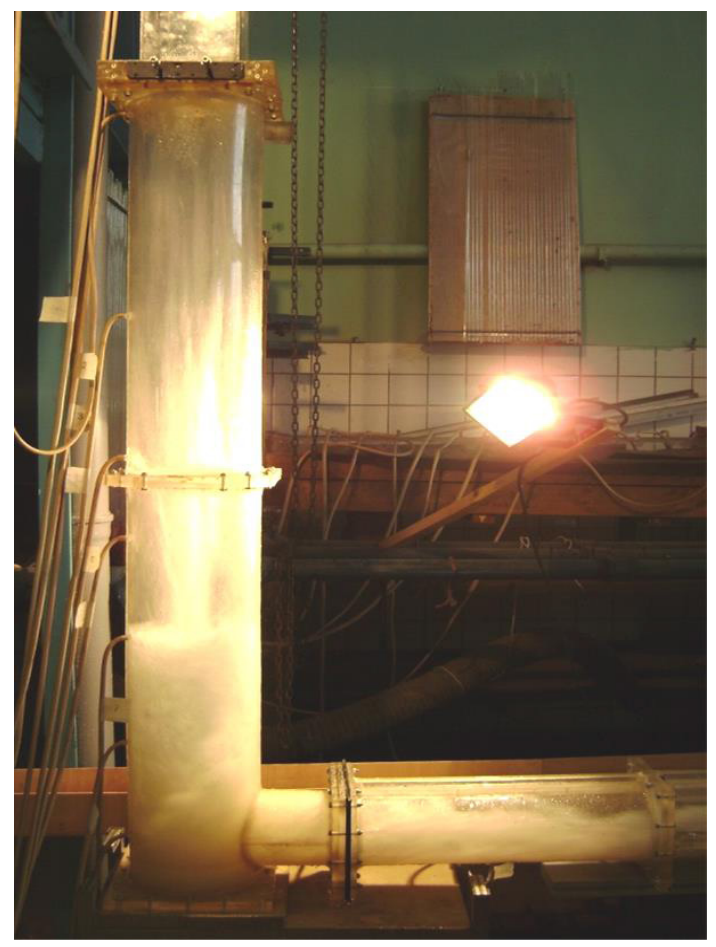

Fig. 19. Movement of water in the abutting zone of the outlet tunnel to the shaft at $Q=180 \mathrm{~m}^{3} / \mathrm{c}$ $Q=180 \mathrm{~m} 3 / \mathrm{s}$ and air supply $Q_{a}=4 \mathrm{~m}^{3} / \mathrm{s}$. 


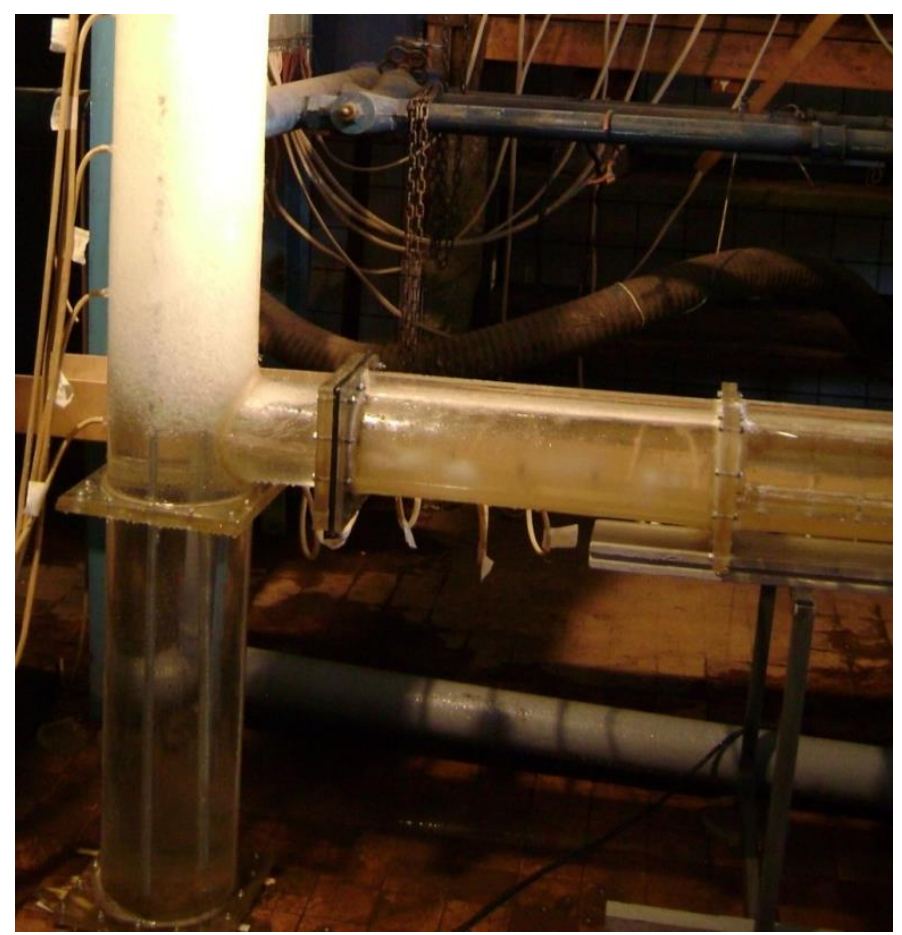

Fig. 20. Movement of water in the abutting zone of the outlet tunnel to the shaft at $Q=630 \mathrm{~m}^{3} / \mathrm{s}$ and air supply $Q_{a}=11 \mathrm{~m}^{3} / \mathrm{s}$.

As shown in Figure 20, in the shaft above the inlet section, the flow is a water-air mixture. But this state of water is observed only starting from the axis level of the tunnel entrance section. Below the axis of the inlet section, the water is completely deaerated, including the shaft appendix below the inlet section. An accumulation of air is observed behind the entrance section of the tunnel over a length of about one diameter under the arch apex. There is an air duct connected by perforation through the tunnel apex to its internal volume down-stream above the tunnel. Since the tunnel is made with a negative slope, the air under the shell moves synchronously with the water and, falling into the perforation zone of the shell, goes into the air duct in a short section. In this case, the tunnel operates in a full cross-section and is filled with a deaerated stream of water.

In the middle of the tunnel, a stable drop-down curve of the free surface of the flow is formed, which can be seen in Figure 21.

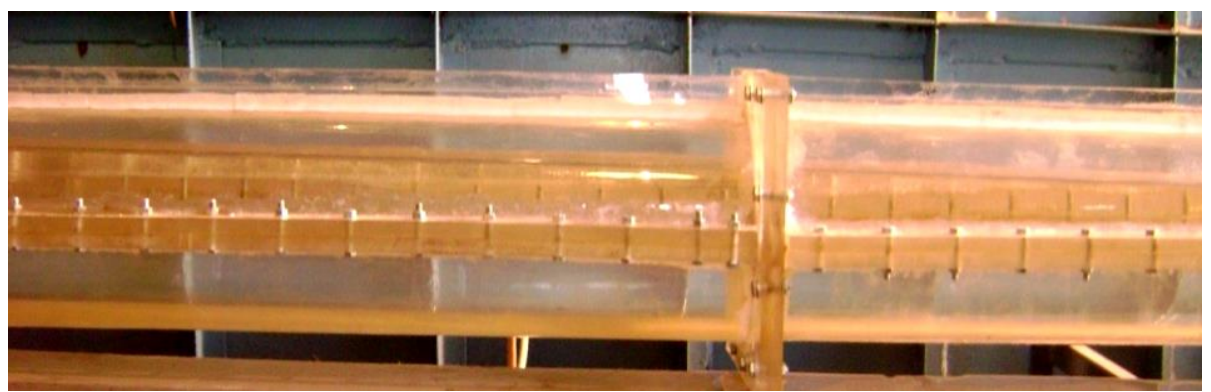

Fig. 21. Pattern of water flow in the middle part of the outlet tunnel with a drop-down curve $Q=630$ $\mathrm{m}^{3} / \mathrm{sc}$ and air supply $Q_{a}=11 \mathrm{~m}^{3} / \mathrm{s}$ 
Figure 22 shows water flow in the water outlet zone at the end section of the tunnel at a spillway flow rate $Q=630 \mathrm{~m}^{3} / \mathrm{s}$ with the air supply $Q_{a}=11 \mathrm{~m}^{3} / \mathrm{s}$.

As shown in Figure 22, at the end of the tunnel, a calm flow was formed with a depth slightly less than half the tunnel's diameter with a calm spreading beyond the exit section.

Figure 23 shows water flow in the zone of water outlet at the tunnel end with an increase in the discharge of the spillway to $Q=2650 \mathrm{~m}^{3} / \mathrm{s}$ with air supply $Q_{a}=50 \mathrm{~m}^{3} / \mathrm{s}$.

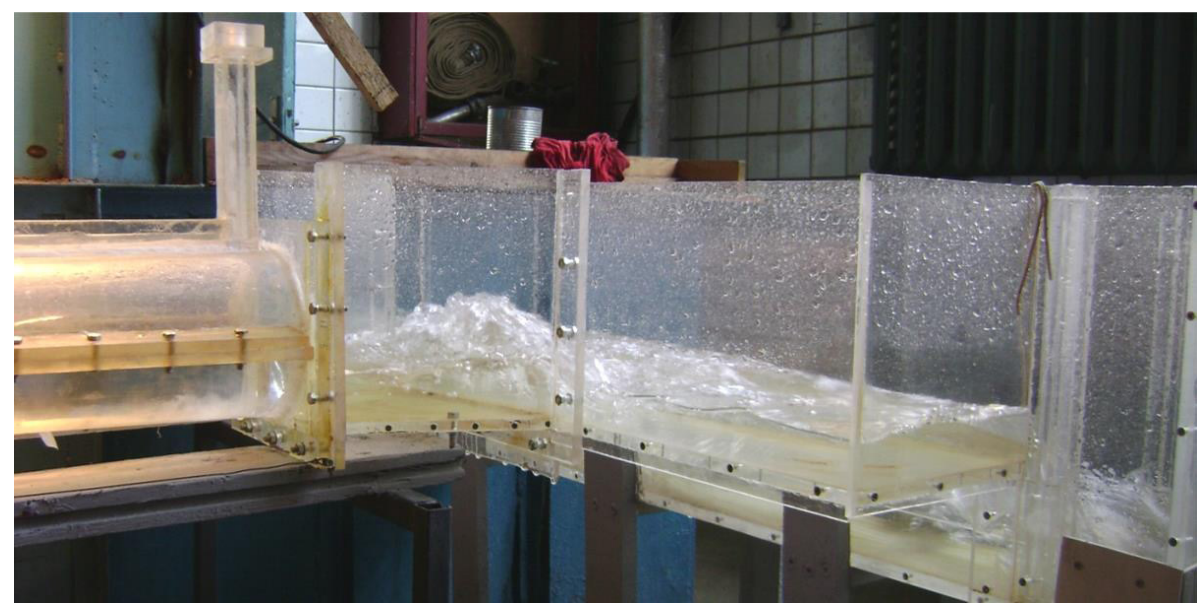

Fig. 22. Pattern of water flow at the end section of the outlet tunnel when air is supplied $Q_{a}=11 \mathrm{~m}^{3} / \mathrm{s}$, $Q=630 \mathrm{~m}^{3} / \mathrm{s}$

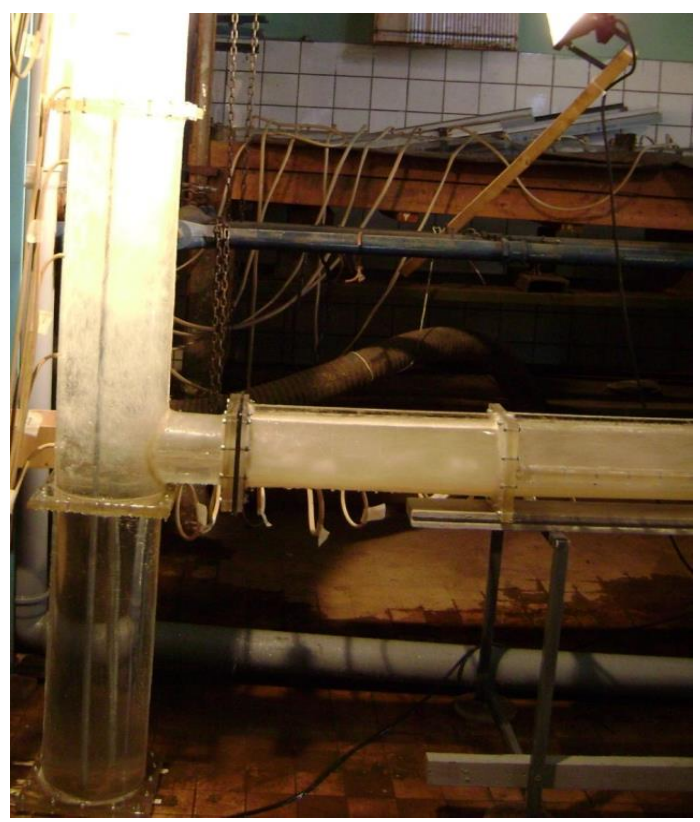

Fig. 23. Pattern of water flow in the abutting zone of the outlet tunnel to the shaft at $Q=2650 \mathrm{~m}^{3} / \mathrm{s}$ and air supply $Q_{a}=50 \mathrm{~m}^{3} / \mathrm{s}$ 


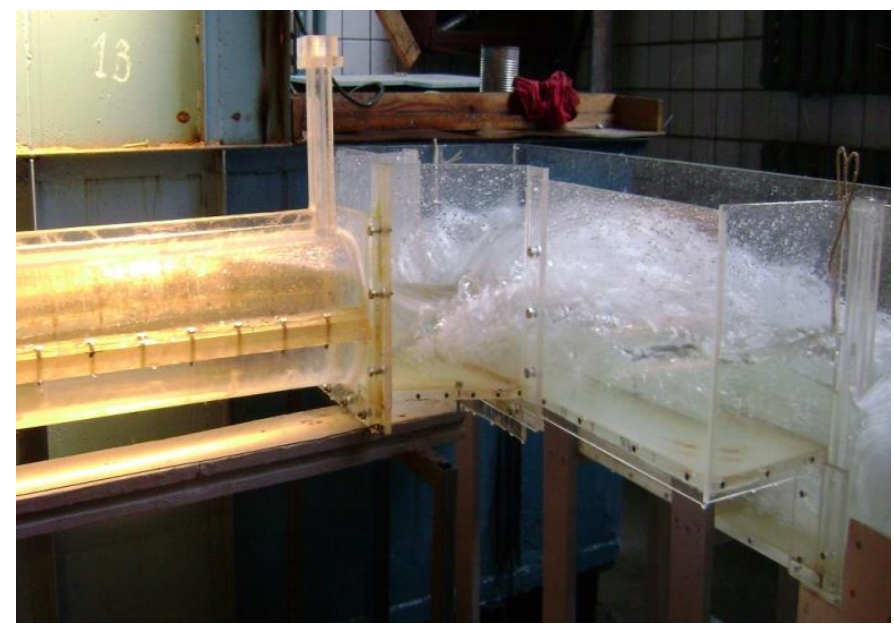

Fig. 24. Pattern of water flow in the area of the end section of the tunnel at $Q=2650 \mathrm{~m}^{3} / \mathrm{s}$ and air supply $Q_{a}=50 \mathrm{~m}^{3} / \mathrm{s}$

Figure 25 shows water flow in the water outlet zone at the end of the tunnel at a maximum spillway flow rate of up to $Q=3130 \mathrm{~m}^{3} / \mathrm{s}$ with air supply $Q_{a}=50 \mathrm{~m}^{3} / \mathrm{s}$, obtained on a model installation. Attention should be paid because this flow rate is 1.73 times higher than the calculated flow rate $Q=1800 \mathrm{~m}^{3} / \mathrm{s}$, adopted for the studied outlet tunnel with a positive slope.

First of all, it should be noted in this experiment that there is a layer of water in the bottom area of the shaft that practically does not contain air bubbles and completely clean water in the upper part of the stilling water well. An increase in the pressure in the form of a depth in front of the inlet section into the outlet tunnel led to the homogenization of the water-air mixture structure in the shaft and the reduced diameter of the air bubbles, which can be seen from the flow state at the initial section of the tunnel.

When the flow rate is $Q=3130 \mathrm{~m}^{3} / \mathrm{s}$ the outlet tunnel operates in a pressure mode along the entire length, with the exception of the end section with a length of about 1.5 of the tunnel diameter. In this section, a drop-down curve and the flow separation from the tunnel apex are formed. This is clearly seen in Figure 26, where there is the end sector of the tunnel, and in Figure 26, b 


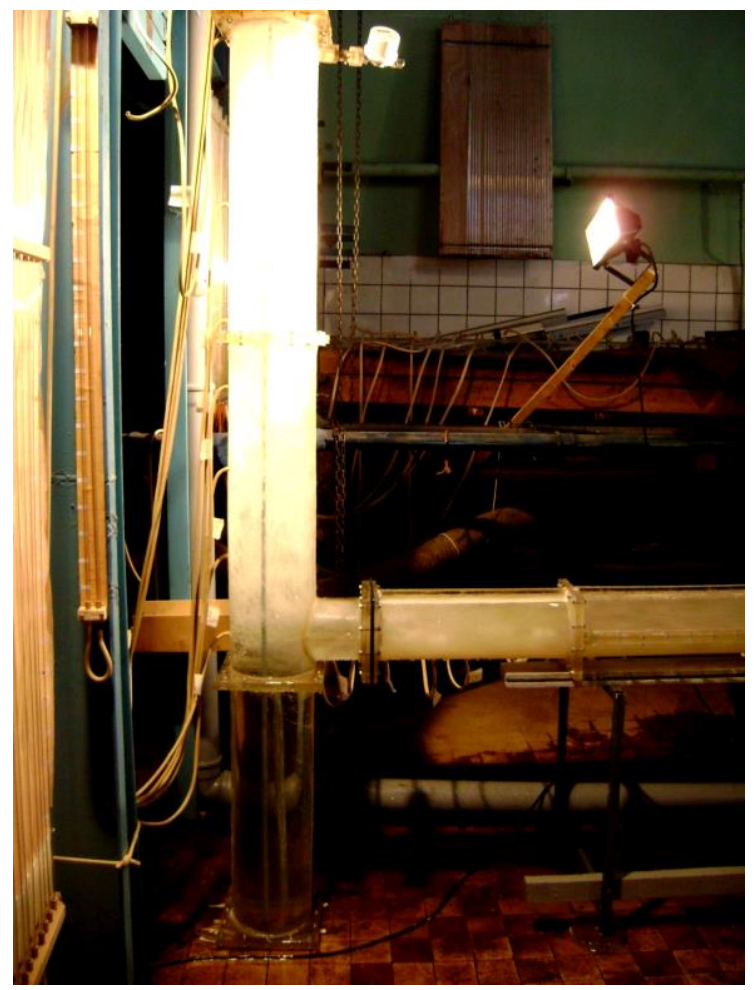

Fig. 25. Pattern of water flow in the abutting zone of the outlet tunnel to the shaft at a maximum flow rate $Q=3130 \mathrm{~m}^{3} / \mathrm{s}$ and air supply $Q_{a}=67 \mathrm{~m}^{3} / \mathrm{s}$

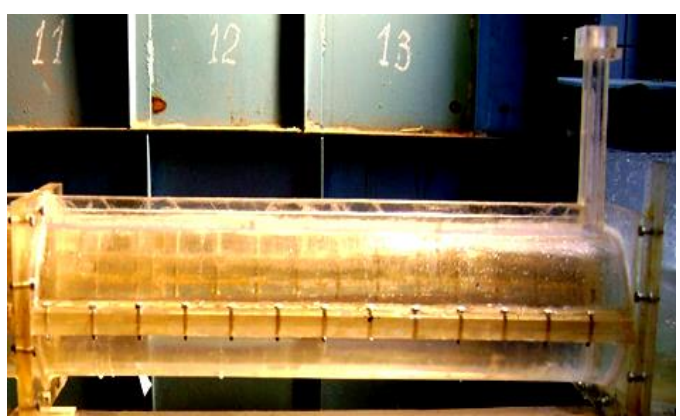

a)

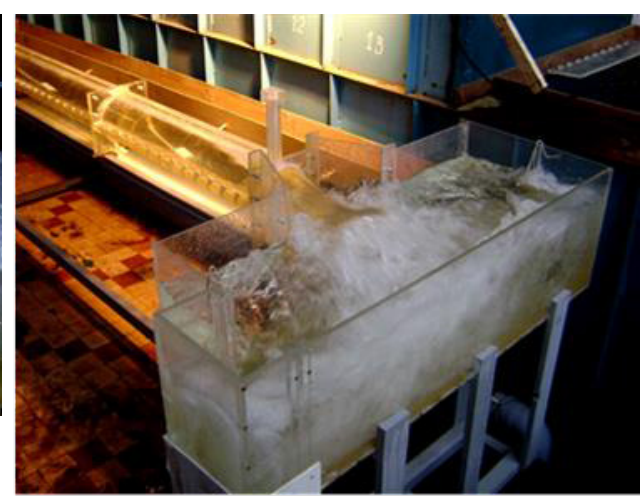

b)

Fig. 26. Pattern of water flow in the zone of the end section of the tunnel at maximum flow rate $Q=3130 \mathrm{~m}^{3} / \mathrm{s}$ and air supply $Q_{a}=67 \mathrm{~m}^{3} / \mathrm{s}: a$ is the end section of the tunnel; $b$ is the exit section of the tunnel and the conjugating structure.

The figure shows the exit section of the tunnel and the conjugating structure with a hydraulic pattern of two-way spreading in the tunnel flow.

\section{Conclusion}

As can be seen from the above illustrations of the operation of an extra energy shaft damper with a metered air supply, when using a dis-charge conduit with a negative slope, it ensures 
the absence of transient modes of operation in the tunnel in the entire range of possible flow rates along the entire length of water flowing out from under the horizontal gates.

The air conduit device located in the tunnel apex provides deaeration of the flow even at the initial section of the tunnel. It prevents the emergence of dynamic operating modes.

The possible scheme of a tunnel with a reverse slope induces the operating modes with increased depths at low and medium flow rates and operation with a full cross-section at increased flow rates compared to the operation of a tunnel with a straight slope. The increase in depths reduces the flow rate and prevents the emergence of cavitation zones.

\section{References}

1. Slisskij S.M. Hydraulic calculations of high-speed hydraulic structure, p. 304, Moscow, (1986).

2. Fink A.K. Shakirov R.R., Leskes A.I., Chesalin Y.V. Hydrotechnical construction, № 11, pp.31-41, Institute Gidroproekt, (2015)

3. Electronic Resource, The coastal spillway of the Sayano-Shushenskaya HPP. https://undergroundexpert.info/opyt-podzemnogo-stroitelstva/realizovannye-

proekty/vodosbros-sayano-shushenskoj-ges/

4. Sudol'skij G.A. Testing the stepped spillway of Boguchanskaya HPP, Hydrotechnical construction, № 9, pp.2-6, (2016)

5. Diversion hydraulic structures (spillways, culverts and outlets). Design rules, 1325800, p. 290, (2016)

6. Gur'yev A.P., Safonova N.A., Hanov N.V. Spillway structure. Patent of the Russian Federation. № 2681568, Bulletin № 8, (11.03.2019)

7. Suhomel G.I., Rozovskij I.L. About the flow of a turbulent stream. Hydrotechnical structures № 1-2, (1946)

8. Berezinskij A.R. Spillway capacity with a wide threshold. Moscow, VODGEO, p. 187 (1950)

9. Smyslov V.V. Theory spillway with a wide threshold. Kiev: Naukova dumka, p. 216, (1966)

10. Gur'yev A.P. Determination of the depths in the cross sections of water conduits bends. Collection of scientific works, MSUEE, part 1. Moscow, (2005)

11. Bazarov D., Vatin N., Obidov B., and Vokhidov O. Hydrodynamic effects of the flow on the slab of the stand in the presence of cavitation. IOP Conf. Ser. Mater. Sci. Eng. 1030, 012110 (2021).

12. Bazarov D., Markova I., Norkulov B. and Vokhidov O. Hydraulic aspects of the layout of head structures during water intake from lowland rivers. IOP Conf. Ser. Mater. Sci. Eng. 1015, 012041 (2021).

13. Bazarov D. and Vokhidov O. Extinguishing Excess Flow Energy in Spillway Structures. In book: Proceedings of EECE 2020, LNCE 150, pp. 535-545, (2021) DOI: 10.1007/978-3-030-72404-7_52

14. Obidov B., Vokhidov O., Tadjieva D., Kurbanova, U., Isakov A. Hydrodynamic effects on the flow elements of the downstream devices in the presence of cavitation. IOP Conf. Ser. Mater. Sci. Eng. 1030, 012114 (2021).

15. Bazarov D., Norkulov B., Vokhidov O., Uljaev F., Ishankulov, Z. Two-dimensional flow movement in the area of protective regulatory structures. IOP Conf. Ser. Mater. Sci. Eng. 890, 012162 (2020) 